\title{
Antimicrobial peptide LL-37 promotes the proliferation and invasion of skin squamous cell carcinoma by upregulating DNA-binding protein A
}

\author{
WEI WANG ${ }^{*}$, JINJING JIA* , CHANGJI LI, QIQI DUAN, JIAO YANG, XIN WANG, \\ RUILIAN LI, CAIFENG CHEN, HULING YAN and YAN ZHENG
}

Department of Dermatology, The Second Affiliated Hospital of Xi'an Jiaotong University, Xi'an, Shaanxi 710004, P.R. China

Received August 22, 2015; Accepted June 29, 2016

DOI: $10.3892 / \mathrm{ol} .2016 .4865$

\begin{abstract}
The antimicrobial peptide LL-37 not only contributes to the host defence against microbial invasion but also regulates immune activity, angiogenesis and cell proliferation. Studies have shown that LL-37 participates in the development of a variety of tumours, such as lung cancer, ovarian cancer, breast cancer and melanoma. However, the role of LL-37 in the development of skin squamous cell carcinoma (SCC) is not clear. The present study used immunohistochemistry to confirm that the expression of human DNA-binding protein A (dbpA) was increased in SCC tissues. After stimulating SCC A341 cells, LL-37 was shown promote the proliferation, migration and invasion of these malignant cells. LL-37 also promoted the upregulation of dbpA mRNA and protein expression. In addition, after using small interfering RNA to silence the normal dbpA expression in these malignant cells, the proliferation and invasion of the tumor cells were significantly reduced. When the NF- $\mathrm{NB}$ inhibitor PDTC was used to inhibit the process of LL-37-stimulated cells, it was found that the original upregulated expression of $\mathrm{dbpA}$ was downregulated. Overall, the present demonstrated that by upregulating the expression of $\mathrm{dbpA}, \mathrm{LL}-37$ can promote the proliferation and invasion of tumour cells, and that this process depends on the NF- $\kappa \mathrm{B}$ signalling pathway.
\end{abstract}

\section{Introduction}

Squamous cell carcinoma (SCC), derived from epidermal keratinocytes of the skin, is one of the most common and

Correspondence to: Dr Yan Zheng, Department of Dermatology, The Second Affiliated Hospital of Xi'an Jiaotong University, 157 Xiwu Road, Xi'an, Shaanxi 710004, P.R. China

E-mail: zenyan66@126.com

*Contributed equally

Key words: LL-37, squamous cell carcinoma, Y-box, DNA-binding protein $\mathrm{A}$, epidermal growth factor receptor, nuclear factor- $\mathrm{\kappa B}$ malignant skin cancers (1), accounting for $20 \%$ of all skin cancers. The disease usually originates from certain types of skin or precancerous lesions. Currently, there are $\sim 1,000,000$ new cases every year, and the number of mortalities from this disease is gradually increasing $(2,3)$.

Human DNA-binding protein A (dbpA) is a multifunctional protein containing a cold shock domain, and it participates in gene transcription and translation by directly or indirectly binding the target gene sequence $(4,5)$. DbpA is primarily expressed in the nucleus and the cytoplasm, and it acts on the transcription, shear action and translation processes of target genes $(6,7)$. Previous studies have shown that dbpA is upregulated in numerous tumour cells, and that this upregulation is associated with the growth of the tumour cells and their resistance to chemotherapy. Therefore, $\mathrm{dbpA}$ is considered a cancer prognosis marker. The overexpression of $\mathrm{dbpA}$ in tumours usually indicates that the proliferation and invasion of tumour cells is increasing (8-10). Additionally, previous studies have found that by regulating the expression of cyclin D1 and upregulating the cell nuclear antigen, dbpA promotes tumour cell proliferation, and that the increase in $\mathrm{dbpA}$ is closely associated with the increase in the transcription factor, E2F transcription factor 1 (E2F1) $(10,11)$. These results demonstrated that $\mathrm{dbpA}$ expression is closely associated with tumour development and progression.

The effect of human anti-microbial protein 18 (hCAP-18) on tumour progression has drawn much attention (12). LL-37 is a cationic peptide composed of 37 -amino acid residues in the hCAP-18 C-terminal, and it is the only cathelin family member in the human body. LL-37 is also an important component of the innate immune system, which is mediated by neutrophils (12-14). In addition to its role against bacterial infection, LL-37 also regulates immune activity, angiogenesis and cell proliferation $(13,15)$. Studies have shown that LL-37 is not only upregulated in a variety of solid tumours, but that it is also involved in the progression mechanisms of a variety of tumours by promoting the proliferation, migration and invasion of lung cancer, ovarian cancer, breast cancer, prostate cancer and melanoma tumour cells (16-21). Additionally, several studies have reported that these features may be associated with formyl peptide receptor-like 1 (FPRL1), epidermal growth factor receptor (EGFR) and insulin-like growth 
factor 1 receptor (14,22-24). It is unclear how LL-37 affects the proliferation and invasion of skin squamous cells. DbpA is associated with tumour proliferation and invasion. However, LL-37 stimulates dbpA expression in skin squamous cells, and its effect on tumour cells is a focus of interest.

In the present study, the effects of LL-37 on dbpA expression and the changes in the dbpA concentration during the proliferation and invasion of skin squamous cells were investigated. The results showed that LL-37 may promote the occurrence and development of skin squamous cells by upregulating dbpA expression and that this process is mediated by the nuclear factor- $\mathrm{\kappa B}(\mathrm{NF}-\mathrm{kB})$ signalling pathway.

\section{Materials and methods}

Tissue collection. Fresh skin SCC and adjacent normal tissues were obtained from 18 patients who underwent surgery at the Department of Dermatological Surgery, Second Affiliated Hospital of Xi'an Jiaotong University (Xi'an, Shaanxi, China). A total of 18 samples of normal tissues and 18 samples of SCC were obtained during surgery. All tissues were embedded in liquid paraffin to form tissue blocks. All skin SCC cases were clinically and pathologically verified. Standard protocols established by the Hospital's Protection of Human Subjects Committee were followed in this study. Written informed consent was obtained from all patients for publication of this study and the study was approved by the Ethics Committee of the Second Affiliated Hospital of Xi'an Jiaotong University.

Immunohistochemistry. The normal skin tissues, the uninvolved tissue of the SCC and the lesions of the SCC were analysed via immunohistochemistry. First, the paraffin-embedded blocks were sliced into $4-\mu \mathrm{m}$ sections and dewaxed in xylene, followed by re-hydration in an alcohol gradient. Next, the tissues were incubated on slides with rabbit anti-human dbpA polyclonal antibody (catalog no. ab48952; Abcam, Cambridge, UK) at a 1:50 dilution. The slides were placed in a humid environment at $4^{\circ} \mathrm{C}$ overnight, washed twice with phosphate-buffered saline (PBS) and incubated in goat anti-rabbit antibody (Abcam) at $37^{\circ} \mathrm{C}$ for $1 \mathrm{~h}$. The slides were then washed twice with PBS, stained with 3,3'-diaminobenzidine (Sigma-Aldrich, Munich, Germany) and observed using a microscope. Next, the slides were rinsed with PBS and re-stained with haematoxylin for $\sim 2 \mathrm{~min}$. After mounting, the results were observed using light microscopy. Normal skin tissue samples were used as the negative controls.

Cell culture. A human SCC cell line (A431) was cultured in F12 medium (Gibco, Karlsruhe, Germany) containing 10\% foetal bovine serum (FBS; Gibco), $100 \mathrm{U} / \mathrm{ml}$ penicillin and $100 \mu \mathrm{g} / \mathrm{ml}$ streptomycin (Sigma-Aldrich). The cells were cultured in a $37^{\circ} \mathrm{C}$ environment containing $5 \% \mathrm{CO}_{2}$.

Inhibiting the dbpA expression using small interfering (si)RNA. The siRNA oligonucleotide sequence was synthesized by Shanghai GenePharma (Shanghai, China) as follows: DbpA siRNA 1, 5'-GUCCUUGGCACUGUCAAAUTT-3' (sense) and 5'-AUUUGACAGUGCCAAGGACTT-3' (antisense); dbpA siRNA 2, 5'-GAGAGGCUGAAGAUAAAG ATT-3' (sense) and 5'-UCUUUAUCUUCAGCCUCUCTT-3' (antisense); and dbpA siRNA 3, 5'-CUGCCAUCAAGAAGA AUAATT-3' (sense) and 5'-UUAUUCUUCUUGAUGGCA GTT-3' (antisense). The negative control duplexes of siRNA (siRNA-NC) were random sequences and did not target any known mammalian gene according to Genbank searches. The cells had a density of $1 \times 10^{5}$ cells/well and were seeded in 6 -well plates. When the fusion reached $70-80 \% \sim 24 \mathrm{~h}$ later, the cells were treated with serum-free medium according to the manufacturer's instructions (Lipofectamine 2000; Invitrogen; Thermo Fisher Scientific Inc., Waltham, MA, USA). Next, the cells were cultured for $48 \mathrm{~h}$, and the dbpA inhibition rate was analysed using western blotting.

Proliferation and invasion assay of the transfected cells. The transfected cells were seeded at a density of $3 \times 10^{3}$ cells/well in 96-well plates. After $12 \mathrm{~h}$, the medium was replaced with serum-free medium and the cells were cultured for another 24 h. Subsequently, $10 \mu 1$ 3-(4,5-dimethylthiazol-2-yl)-2,5-diphenyltetrazolium bromide (MTT; $5 \mathrm{mg} / \mathrm{ml}$; Sigma-Aldrich) was added to each well and incubated for an additional $4 \mathrm{~h}$. The supernatant was discarded and $150 \mu \mathrm{l}$ dimethyl sulphoxide (Sigma-Aldrich) was added. The absorbance of each well was measured at $490 \mathrm{~nm}$ using a microplate reader (Bio-Rad Laboratories Inc., Hercules, CA, USA). The invasion assay was performed using Transwell chambers (Costar; Corning Inc., Corning, NY, USA) pre-coated with Matrigel (BD Biosciences, Heidelberg, Germany). The transfected cells were cultured without serum for $12 \mathrm{~h}$ and then resuspended in serum-free medium, with the density adjusted to $2.5 \times 10^{5}$ cells $/ \mathrm{ml}$. Next, $200 \mu 1$ of cell suspension was added to each Transwell chamber, and $500 \mu \mathrm{l}$ of culture medium with $10 \%$ FBS was added to the lower chamber. After culturing for $24 \mathrm{~h}$, the residual cells on the surface were gently wiped away using a cotton swab. The cells that invaded the lower chamber were stained with a staining solution $(0.1 \%$ crystal violet ethanol). Under a microscope (x200 magnification), three representative fields were randomly selected and the average number of invaded cells was calculated.

Cell proliferation assay. The cells were seeded at a density of $3 \times 10^{3}$ cells/well in 96-well plates. After $12 \mathrm{~h}$, the medium was replaced with serum-free medium and the cells were cultured for an additional $24 \mathrm{~h}$. The LL-37 (Sigma-Aldrich, Munich, Germany) was used to stimulate the cells at $10 \mathrm{mg} / \mathrm{ml}$ for 24, 48 and $72 \mathrm{~h}$. Next, the aforementioned MTT assay was used to evaluate the degree of cell proliferation.

Migration and invasion assay after LL-37 stimulation. The aforementioned Transwell assays were used to test cell migration and invasion abilities after LL-37 stimulation. In the upper chamber, a specific concentration $(0.05,0.5$ or $5 \mu \mathrm{g} / \mathrm{ml})$ of LL-37 was added. The chambers with pre-coated Matrigel were used for invasion assays or without Matrigel for migration assays.

Total RNA extraction and quantitative polymerase chain reaction ( $q P C R$ ). TRIzol reagent (Sigma-Aldrich) was used to extract total RNA from the A431 cells after stimulation by LL-37. The total RNA ( $3 \mu \mathrm{g})$ was reverse transcribed to cDNA in a total volume of $20 \mu$ using a reverse transcription 
reaction kit (Promega Corporation, Madison, WI, USA). qPCR was performed using an Mx 3000P Real-Time PCR system (Applied Biosystems; Thermo Fisher Scientific Inc.) according to the manufacturer's instructions. SYBR Premix Ex Taq II (Takara Biotechnologies Co., Ltd., Dalian, China) was used as a DNA-specific fluorescent dye. PCR was performed for 50 cycles of $95^{\circ} \mathrm{C}$ for $10 \mathrm{sec}$ and $60^{\circ} \mathrm{C}$ for $30 \mathrm{sec}$. Primer sequences for the detection of mRNA expression were synthesized as follows: DbpA specific primers, 5-CTCTACAGTTTC TCCATCTCCTAC-3 (forward) and 5-TTCTCGCCACCA AAGTCCT-3 (reverse); and human $\beta$-actin primers, 5-TTC CATATCGTCCCAGTTGGT-3 (forward) and 5-CCAGGG CGTTATGGTAGGCA-3 (reverse). The dbpA transcriptional level was corrected based on the corresponding level of $\beta$-actin transcription. All the values are from the results of at least three independent experiments.

Immunofluorescence staining. Once a monolayer of cells had been placed on the climbing film, LL-37 of the appropriate concentration $(0.05,0.5$ or $5 \mu \mathrm{g} / \mathrm{ml})$ was added for $48 \mathrm{~h}$. The cells were then fixed with $4 \%$ paraformaldehyde at room temperature for $10 \mathrm{~min}$, followed by permeabilisation with 5\% Triton X100 (Sigma-Aldrich) for $15 \mathrm{~min}$. The cells were then blocked with $2 \%$ goat serum for $30 \mathrm{~min}$. The cells were incubated with a rabbit anti-human dbpA polyclonal antibody diluted at 1:50 (Abcam) overnight at $4^{\circ} \mathrm{C}$, and washed 3 times with PBS. The cells were incubated with fluorescein isothiocyanate-labelled goat anti-rabbit antibody (Abcam) at $37^{\circ} \mathrm{C}$ for $1 \mathrm{~h}$, washed with PBS 3 times and finally stained with DAPI (Sigma, Munich, Germany) for $1 \mathrm{~min}$. The cells were rinsed with PBS and the staining intensity was observed using an inverted fluorescence microscope (LSM 700; Zeiss GmbH, Jena, Germany).

Protein extraction and western blot analysis. Total protein was extracted following LL-37 stimulation. Protein isolates $(\sim 10 \mu \mathrm{g})$ from each sample were separated with $10 \%$ sodium dodecyl sulfate-polyacrylamide gel electrophoresis and transferred to a polyvinylidene difluoride membrane. The membrane was blocked with $5 \%$ skimmed milk and a $0.1 \%$ Tween-20 phosphate-buffered solution at room temperature for $2 \mathrm{~h}$, and then treated with rabbit polyclonal anti-human dbpA antibody diluted at 1:500 (Abcam) at $4^{\circ} \mathrm{C}$ overnight. Next, it was hybridized with secondary antibody $(1: 5,000$, Abcam) for $1 \mathrm{~h}$. The results were detected by exposing the film to enhanced chemiluminescence colour detection solutions (EMD Millipore, Billerica, MA, USA).

Analysis of the signal transduction pathways of the dbpA induction by LL-37. The SCC cells were seeded at $1 \times 10^{5}$ cells/well in 6 -well plates. First, the cells were treated with the mitogen-activated protein kinase (MAPK) kinase (MEK) inhibitor, PD98059 (10 $\mu \mathrm{M}$; Abcam), the p38/MAPK inhibitor, SB203580 (10 $\mu \mathrm{M}$; Abcam) and the NF- $\kappa$ B inhibitor, PDTC (1 $\mu \mathrm{M}$; Abcam), for $30 \mathrm{~min}$. Next, LL-37 $(0.5 \mu \mathrm{M})$ was added for $24 \mathrm{~h}$. The protein was then extracted for western blot analysis.

Statistical analysis. All data are presented as the mean \pm standard deviation. Pearson's $\chi^{2}$ test was used for the

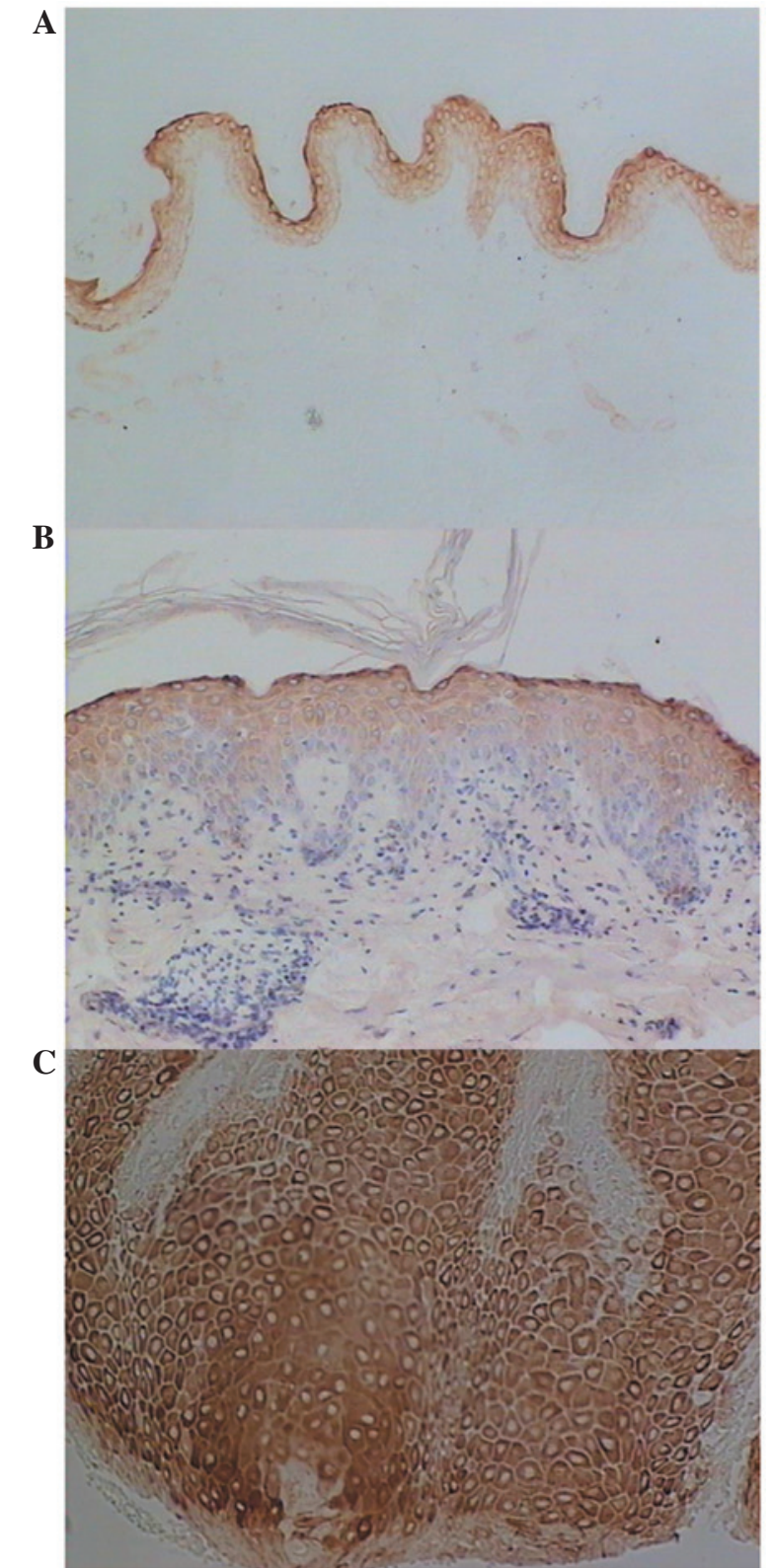

Figure 1. Immunohistochemical analysis of dbpA expression in (A) normal skin, (B) in tissue surrounding the SCC and (C) in SCC. In SCC, dbpA expression was stronger than in normal skin tissue. Magnification: (A) x100, (B) x200 and (C) x200. SCC, squamous cell carcinoma; dbpA, DNA-binding protein A.

immunohistochemical analysis. Student's t-test was used for comparisons between groups and an analysis of variance was used for three or more groups. All analyses were performed using SPSS 13.0 (SPSS Inc, Chicago, IL, USA). Results were considered statistically significant at $\mathrm{P}<0.05$.

\section{Results}

$D b p A$ is upregulated in SCC. In the normal skin tissues, the $\mathrm{dbpA}$ protein was strongly expressed in the granular layers and weakly expressed in the upper layers of the stratum spinosum (Fig. 1A), and the positive rate in the stratum spinosum was $20.0 \%(4 / 20)$. In the uninvolved epidermis of SCC, dbpA was strongly expressed in the granular layers and in the upper layers of the stratum spinosum (Fig. 1B), and the positive rate 


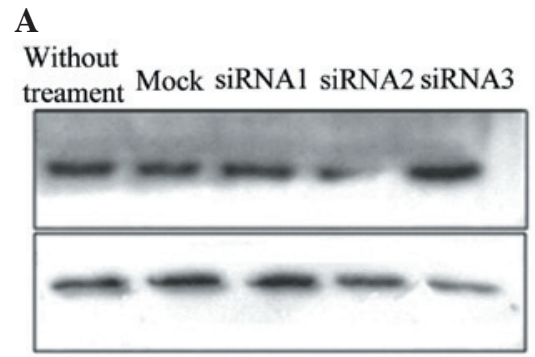

A431 (24 h)

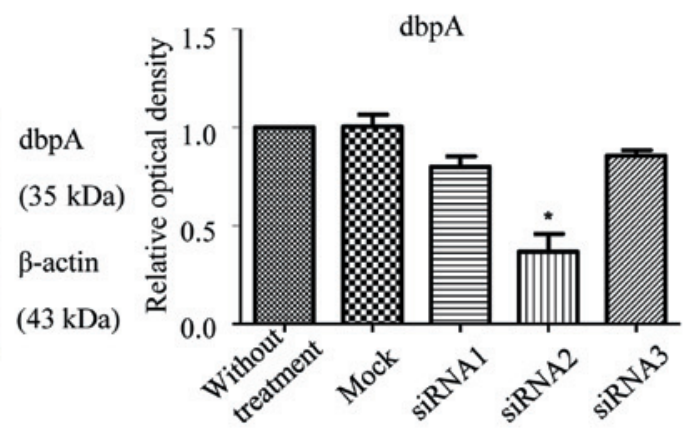

B

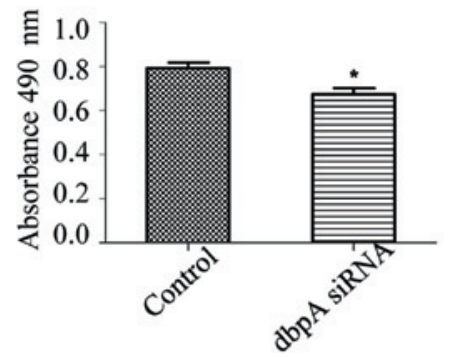

C

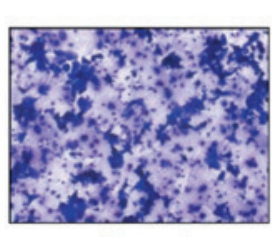

Control

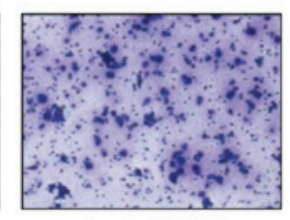

dbpA siRNA

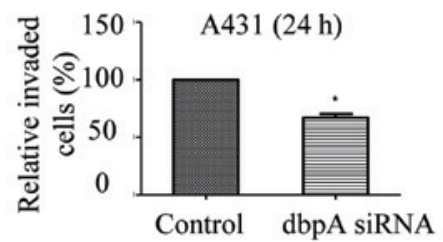

D

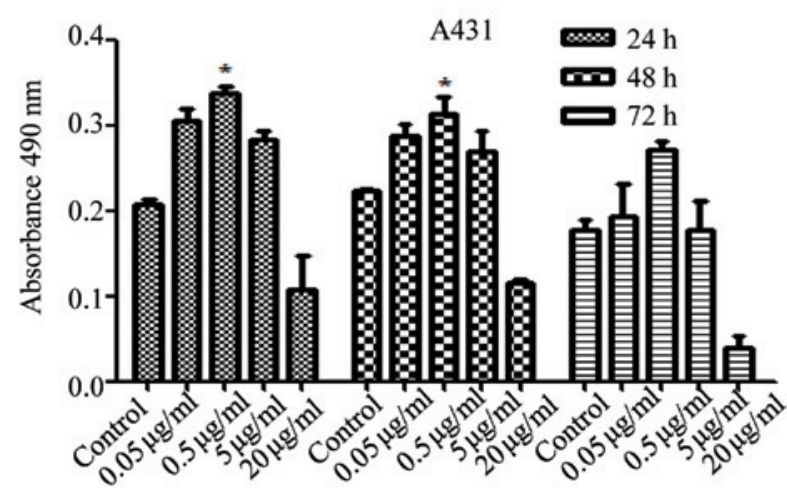

Figure 2. (A) Expression of dbpA in A431 cells after treatment with dbpA siRNA. Western blot analysis of dbpA and $\beta$-actin expression in the dbpA siRNA(1-3) and control siRNA groups. (B) DbpA siRNA reduced the proliferation ability in the A431 cells. After treatment with dbpA siRNA for 24 h, an MTT assay was performed to analyse cell proliferation by reading absorbance at $490 \mathrm{~nm}$ in each well using an automatic microplate reader and (C) the invasion ability of the cells was also assessed (magnification, x200). (D) The proliferation of the A431 cells was promoted by culturing with $0.05,0.5,5$ or $20 \mu \mathrm{g} / \mathrm{ml} \mathrm{LL}-37$ for 24,48 or $72 \mathrm{~h}$. Cell proliferation levels were also analysed by MTT assay. The results from three independent experiments are shown as the mean \pm standard deviation. $\mathrm{n}=5$ samples in each group. ${ }^{*} \mathrm{P}<0.05$ vs. control. siRNA, small interfering RNA; dbpA, DNA-binding protein A; MTT, 3-(4,5-dimethylthiazol-2-yl)2,5-diphenyltetrazolium bromide.

in the stratum spinosum was $27.8 \%$ (5/18). However, in SCC, $\mathrm{dbpA}$ was detected in significant quantities in nearly all of the tumour cells (Fig. 1C), and the positive rate was $83.3 \%$ (15/18). The dbpA expression in SCC was stronger than that in the normal skin tissues $\left(\chi^{2}=15.5 ; \mathrm{P}<0.01\right)$ or the uninvolved epidermis $\left(\chi^{2}=10.7 ; \mathrm{P}<0.01\right)$.

$d b p A$ siRNA decreases the protein levels of $d b p A$, and reduces the proliferation and invasion of the SCC cells. After $48 \mathrm{~h}$ of culture, total protein was extracted from the transfected cells and analysed using western blotting. Compared with the control group, the protein expression of $\mathrm{dbpA}$ in the $\mathrm{dbpA}$ siRNA 2 group was significantly reduced ( $\mathrm{P}=0.008$; Fig. $2 \mathrm{~A})$; thus, dbpA siRNA 2 was chosen for the subsequent experiments. Compared with the control group, cell proliferation in the presence of the siRNA decreased after $24 \mathrm{~h}$, indicating that the $\mathrm{dbpA}$ expression was correlated with the proliferation of the tumour cells ( $\mathrm{P}=0.028$; Fig. 2B). Transwell chambers coated with Matrigel were used to study the invasion ability of the A431 cells after inhibiting the $\mathrm{dbpA}$ expression. Compared with the control group, the number of invading cells that crossed the membranes diminished after $24 \mathrm{~h}$, indicating that $\mathrm{dbpA}$ was correlated with the invasiveness of the tumour cells $(\mathrm{P}<0.034$; Fig. 2C). Thus, the inhibition of $\mathrm{dbpA}$ may reduce the proliferation and invasiveness of A431 cells.

LL-37 promotes the proliferation of SCC cells. The A431 cells were stimulated using different concentrations of LL-37 and its effect on the cell proliferation was observed at various time intervals. Compared with the control group, stimulation with LL-37 at different times and concentrations increased the proliferation of the A431 cells (Fig. 2D), and these increases were significant for 24 or $48 \mathrm{~h}$ of culture with $0.5 \mu \mathrm{g} / \mathrm{ml}$ of LL-37 ( $\mathrm{P}=0.028)$.

LL-37 promotes the migration and invasion of SCC cells. Compared with the control group, different concentrations of LL-37 enhanced the migration of the A431 cells after $12 \mathrm{~h}$ of culture $(\mathrm{P}=0.001$; Fig. $3 \mathrm{~A})$ and the invasiveness of the $\mathrm{A} 431$ cells after $24 \mathrm{~h}$ of culture (Fig. 3B). The most effective concentration was $0.5 \mu \mathrm{g} / \mathrm{ml}(\mathrm{P}=0.002)$.

\section{LL-37 promotes the $m R N A$ and protein expression of $d b p A$} in SCC cells. Compared with the control group, stimulation of the A431 cells with LL-37 for $36 \mathrm{~h}$ increased the mRNA expression of $\mathrm{dbpA}(\mathrm{P}=0.004)$, with the most significant increase observed for $0.5 \mu \mathrm{g} / \mathrm{ml} \mathrm{LL}-37$ ( $\mathrm{P}=0.003$; Fig. 3C) . Western blot showed that after stimulating the A431 cells with LL-37 for $72 \mathrm{~h}$, the protein expression of dbpA increased $(\mathrm{P}=0.041$; Fig. 4A) and again, the most significant increase was observed for $0.5 \mu \mathrm{g} / \mathrm{ml} \mathrm{LL}-37$ ( $\mathrm{P}=0.029$; Fig. 4B). Moreover, stimulating the A431 cells with various concentrations of LL-37 increased the fluorescence intensity of dbpA immunostaining, and $0.5 \mu \mathrm{g} / \mathrm{ml}$ was the most effective concentration (Fig. 4C). Thus, LL-37 promoted the expression of dbpA in the A431 cells. 
A
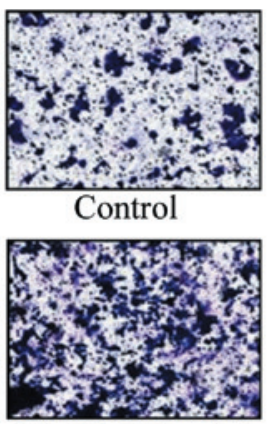

LL-37 $0.5 \mu \mathrm{g} / \mathrm{ml}$

B

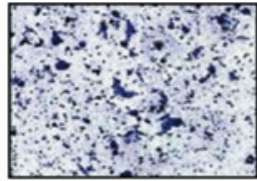

Control

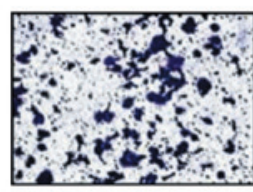

LL-37 $0.5 \mu \mathrm{g} / \mathrm{ml}$
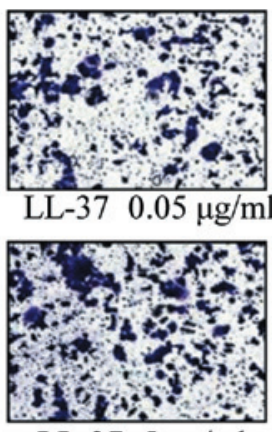

LL-37 $5 \mu \mathrm{g} / \mathrm{ml}$

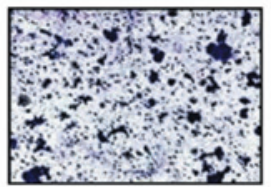

LL-37 $0.05 \mu \mathrm{g} / \mathrm{ml}$

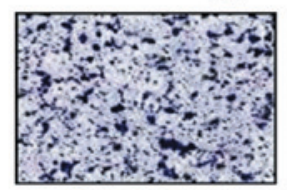

LL-37 $5 \mu \mathrm{g} / \mathrm{ml}$
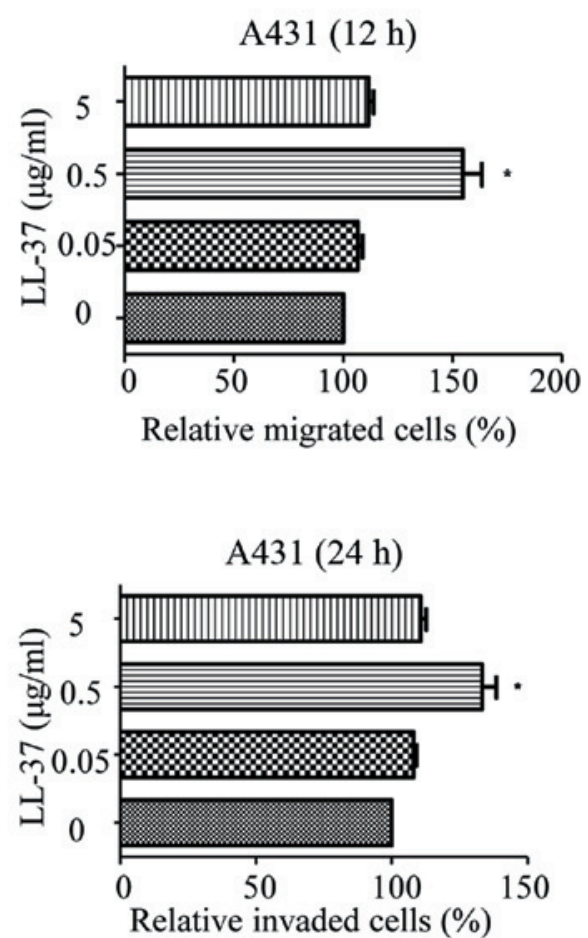

C

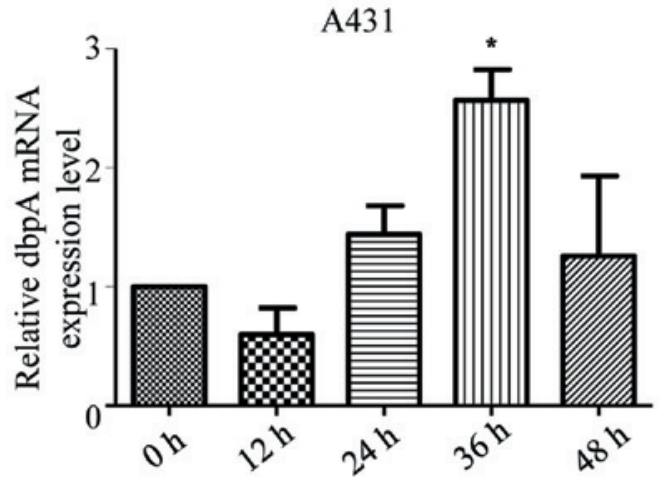

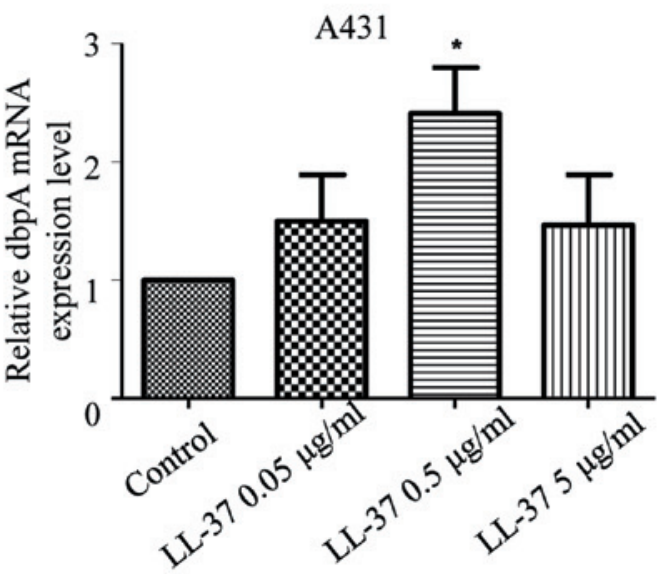

Figure 3. (A) LL-37 induces migration in A431 cells. Serum-starved A431 were treated with LL-37 at $0.05,0.5$ and $5 \mu \mathrm{g} / \mathrm{ml}$ of LL-37 for $12 \mathrm{~h}$, and the cell migration was analysed. (B) LL-37 induces invasion of A431 cells. Serum-starved A431 cells were treated with LL-37 at $0.05,0.5$ and $5 \mu \mathrm{g} / \mathrm{ml}$ of LL-37 for $24 \mathrm{~h}$, and the cell invasion was analysed. Magnification, $\mathrm{x} 200$. The results from three random fields are shown and presented as the mean \pm standard deviation. (C) LL-37 promotes the upregulation of dbpA mRNA in A431 cells. Time effect: A431 cells were stimulated with $0.5 \mu \mathrm{g} / \mathrm{ml} \mathrm{LL}-37$ for the specified durations. Dose effects: A431 cells were stimulated with the specified doses of LL-37 for $24 \mathrm{~h}$. DbpA mRNA levels were determined by quantitative polymerase chain reaction. The figure shows the ratio of dbpA mRNA/ $\beta$-actin mRNA. ${ }^{*}<<0.05$ vs. control, 0 h or $0 \mu \mathrm{g} / \mathrm{ml}$. siRNA, small interfering RNA; dbpA, DNA-binding protein A.

An $N F-\kappa B$ inhibitor inhibits dbpA expression induced by LL-37 in SCC cells. To study the signalling pathway downstream of LL-37 that induced the expression of dbpA, inhibition experiments were performed. The A431 cells were pretreated with the MEK inhibitor, PD98059, the p38/MAPK inhibitor, SB203580, and the NF- $\kappa$ B inhibitor, PDTC, to inhibit the effect of LL-37 on the induction of dbpA expression. PDTC significantly inhibited the LL-37-induced expression of $\mathrm{dbpA}$ in the A431 cells $(\mathrm{P}=0.011$; Fig. 4D), indicating that the increased $\mathrm{dbpA}$ expression that was stimulated by LL-37 may occur via an NF- $\mathrm{KB}$ signalling pathway.

\section{Discussion}

The present results indicated that $\mathrm{dbpA}$ was not expressed in the basal layer in normal skin tissue, but its expression increased in SCC as it was expressed in almost all of the tumour cells. When stimulated by LL-37, the protein level of dbpA increased in the cutaneous SCC cells in a time- and concentration-dependent manner. The inhibition of the $\mathrm{NF}-\kappa \mathrm{B}$ signalling pathway led to a lower amount of LL-37-induced $\mathrm{dbpA}$ protein expression in the A431 cells. This indicated that LL-37 could regulate the expression of $\mathrm{dbpA}$ in the A431 cells and that this process may occur via the activation of the $\mathrm{NF}-\kappa \mathrm{B}$ signalling pathway. 
A
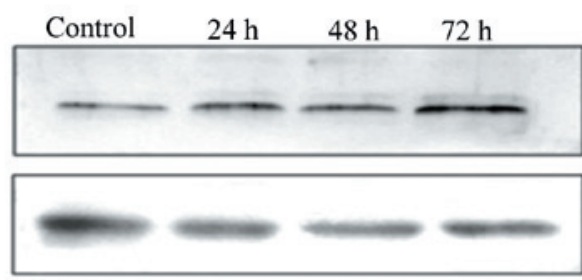

$\beta$-actin

$(43 \mathrm{kDa})$

B

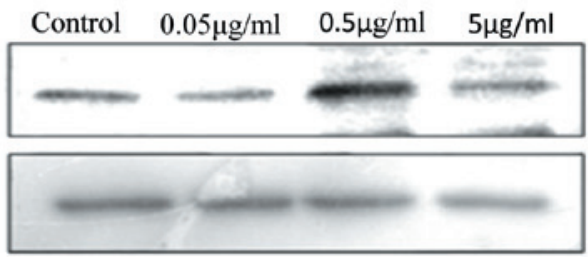

dbpA

$(35 \mathrm{kDa})$

$\beta$-actin

(43kDa)
C

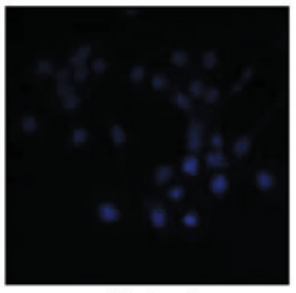

Control

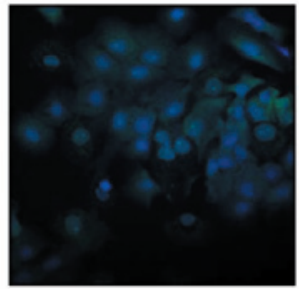

LL-37 $0.05 \mu \mathrm{g} / \mathrm{ml}$
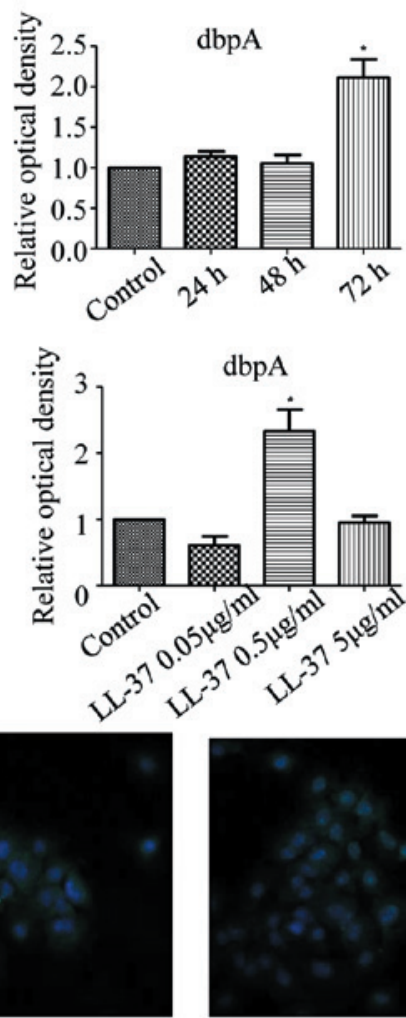

LL-37 $0.5 \mu \mathrm{g} / \mathrm{ml}$

dbpA

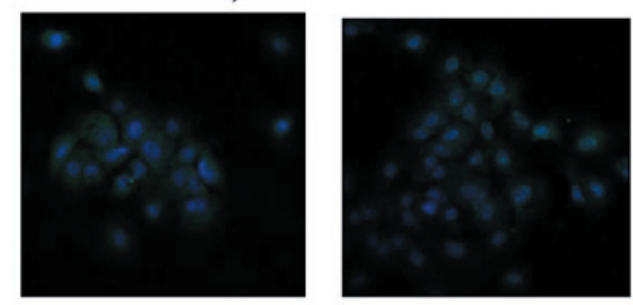

LL-37 $5 \mu \mathrm{g} / \mathrm{ml}$

D
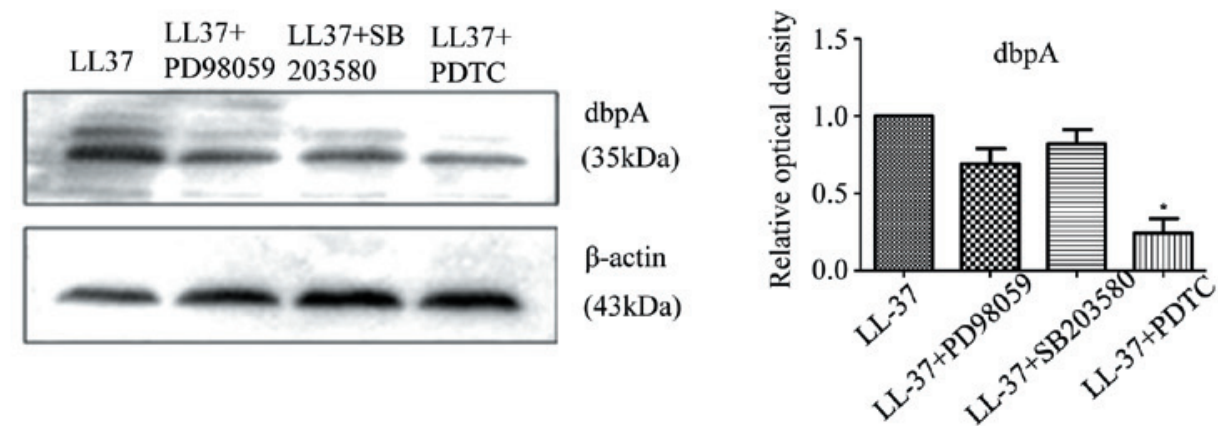

Figure 4. (A and B) LL-37 promotes the upregulation of dbpA protein in A431 cells. Time effect: A431 cells were stimulated with $0.5 \mu \mathrm{g} / \mathrm{ml} \mathrm{LL}-37$ for the specified durations. Dose effect: A431 cells were stimulated with the specified doses of LL-37 for $48 \mathrm{~h}$. DbpA protein levels were determined by western blotting. The figure shows the ratio of $\mathrm{dbpA}$ protein/ $\beta$-actin protein. The results from three independent experiments are shown as the mean \pm standard deviation. (C) LL-37 promotes the upregulation of dbpA protein in A431 cells. The A431 cells were stimulated with the specified dose of LL-37 for $48 \mathrm{~h}$, and dbpA protein expression levels were determined by immunofluorescence. The figures show dbpA protein fluorescence intensity after stimulation by different concentrations of LL-37. Magnification, x400. (D) The NF-kB signalling pathway is involved in the upregulation of dbpA stimulated by LL-37 in A431 cells. The A431 cells were pretreated for $30 \mathrm{~min}$ with MAPK kinase-extracellular signal-regulated kinase inhibitor (PD98059; $10 \mu \mathrm{M}$ ), MAPK inhibitors (SB203580, $10 \mu \mathrm{M}$ ) or NF- $\mathrm{BB}$ inhibitor (PDTC; $1 \mu \mathrm{M}$ ), followed by treatment with $0.5 \mu \mathrm{g} / \mathrm{ml} \mathrm{LL}-37$ for $48 \mathrm{~h}$. The protein levels of dbpA were determined by western blotting. The figure shows the ratio of dbpA protein/ $\beta$-actin protein. The results from three independent experiments are shown as the mean \pm standard deviation.

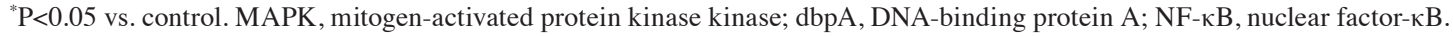

LL-37 is a member of the antibacterial peptide family and is correlated with the proliferation of epidermal cells $(13,14)$. Previous studies have shown that LL-37 can promote malignant tumours, including lung cancer, ovarian cancer, melanoma, prostate cancer and oral SCC, and this process is primarily associated with the upregulation of EGFR and the receptor tyrosine kinase ErbB2 (25). Through the induction of the membrane-associated protein kinase, EGFRs cleave the matrix metalloproteinase (MMP), and LL-37 activates EGFR. This process may be dependent on the $\mathrm{G}$ protein-coupled receptors (GPCRs) present in different cell types (14,22-24). In lung SCC, LL-37 stimulates the proliferation and invasion of tumour cells, accompanied by its mitogenic effect of EGFR phosphorylation and the subsequent activation of the Ras/MAPK cascade. EGFR signalling in lung cancer cells plays a direct role in proliferation, anti-apoptosis, angiogenesis generation, invasion and metastasis $(14,21)$. The majority of the EGFR ligands, such as transforming growth factor and heparin-binding epidermal growth factor, are expressed as soluble transmembrane precursors that are released after cleavage by a protease. These precursors can diffuse freely and bind and activate EGFR. Thus, the 
oncogenic effect of LL-37 in certain tissues occurs via the activation of the EGFR-mediated transcriptional mechanism $(23,26,27)$. In breast cancer, LL-37 promotes tumour progression via the ErbB-mediated pathway, upregulating the expression of ErbB2 or EGFR to enhance ErbB signalling, thereby promoting growth and metastasis (19). Additionally, formyl peptide receptor 2 (FPR2) may be involved in this process. LL-37 stimulates the activation of MAPK and Janus kinase/signal transducer and activator of transcription and undergoes a biochemical cascade with transcription factor signalling, thereby leading to significant activation of several transcription factors. This process may be dependent on FPR 2 or may be independent of it $(22,24,28)$. In ovarian cancer, the fact that LL-37 may stimulate cell proliferation has been considered not dependent of the GPCR. However, LL-37 enhances the invasiveness of ovarian cancer cells via the upregulation of tissue remodelling enzymes, such as MMP-2, and this enhancement is GPCR-mediated. FPR2 in ovarian cancer cells can increase the expression of MMP-2, thus inhibiting or blocking the invasive ability of the receptors of LL-37 and thereby promoting the invasiveness of tumour cells $(20,23,26,27)$. Previous studies have shown that the $\mathrm{Y}$ box binding protein (Y-BOX) family member of $\mathrm{dbpA}$ could regulate the proliferation of epithelial cells and is abnormally expressed in liver cancer, stomach cancer and other tumours (29-32). In transgenic mice, the increase in FPR2 can promote the expression of dbpA mRNA $(11,33)$. Studies have also suggested that proteins of the Y-BOX family regulate the expression of EGFR and ErbB2. By binding to the EGFR receptor, Y-BOX proteins regulate the transcription of these receptors by binding to the enhancer region of the EGFR gene and to the promoter region of the ErbB2 (HER-2/neu) gene. EGFR and ErbB2 are considered to be associated with the proliferation and invasion of epidermal tumours to increase the degree of malignancy $(6,8)$. A previous study showed that the upregulation of $\mathrm{dbpA}$ during cell proliferation is due to the upregulation of E2F1 activity. The E2F1 activity in cell proliferation and apoptosis is extremely important. Therefore, $\mathrm{dbpA}$ is a downstream target of E2F1 that promotes cell proliferation and transformation $(10,34)$.

The results of the present study showed that the expression of $\mathrm{dbpA}$ is increased in SCC. siRNA was used to inhibit the expression of dbpA in A431 cells, and in vitro MTT and Transwell invasion assays confirmed that the reduced expression of $\mathrm{dbpA}$ inhibits the proliferation and invasion of A431 cells. The A431 cells were stimulated with LL-37, and it was found that $\mathrm{dbpA}$ mRNA expression increased as a function of time and concentration. Immunofluorescence and western-blot analyses were used to detect the dbpA cell protein expression changes in the A431 cells and dbpA protein expression was also found to increase as a function of time and concentration. These results suggested that LL-37 can upregulate dbpA expression in A431 cells. A previous study (35) reported that LL-37 increases the degree of malignancy of tumour cells, and that this is associated with the Ras/MAPK signalling cascade and the NF- $\mathrm{B}$ pathway. Therefore, inhibitors of the extracellular signal-regulated kinase, MAPK and NF- $\mathrm{B}$ signalling pathways were tested and it was found that the increase in $\mathrm{dbpA}$ protein expression that was induced by LL-37 could be blocked by the NF-кB inhibitor. This result indicated that LL-37 upregulates dbpA expression via the $\mathrm{NF}-\kappa \mathrm{B}$ signalling pathway. Through the induction of EGFR to cleave MMP-2, LL-37 activates EGFR and ErbB2, accompanied by the phosphorylation of EGFR and the activation of the downstream Ras/MAPK cascade. This enhances the ErbB signal and promotes the expression of MMP-2 via FPR2. Thus, EGFR, ErbB2 and FPR 2 are involved in the regulation of $\mathrm{dbpA}$ expression, and the overexpression of these factors may increase the proliferation and invasion of tumour cells, indicating that that LL-37 promotes the proliferation and invasion of A431 cells by upregulating dbpA expression. $\mathrm{NF}-\kappa \mathrm{B}$ is a transcription factor that is known to regulate the expression of multiple genes and is involved in a wide range of cellular responses. When found in tumour cells, LL-37 can increase the levels of $\mathrm{NF}-\kappa \mathrm{B}$ p65, which can regulate the expression of genes, such cyclin D1, to promote cell growth. The activation of $\mathrm{NF}-\kappa \mathrm{B}$ has a significant role in promoting metastasis, and inhibiting $\mathrm{NF}-\kappa \mathrm{B}$ can prevent the apoptotic process in tumour cells (36). The present study showed that the inhibition of the NF- $\mathrm{NB}$ signalling pathway suppressed the upregulation of dbpA that was induced by the LL-37 in A431 cells, indicating that this process is associated with the $\mathrm{NF}-\kappa \mathrm{B}$ signalling pathway.

In conclusion, the present study confirms that the expression of dbpA is increased in SCC, and that it can be a marker for the degree of malignancy. The antimicrobial peptide LL-37 upregulates dbpA expression and promotes proliferation and invasion in A431 cells. This process may be regulated by the activation of the NF- $\kappa \mathrm{B}$ signalling pathway. This study introduces a novel perspective on the association between LL-37 and dbpA in SCC, and provides a possible strategy for clinical drug development.

\section{Acknowledgements}

This study was supported by the National Natural Science Foundation of China (grant nos. 81071299, 81371732 and 81573055 ) and was partially supported by the Fundamental Research Funds for the Central Universities and for Changjiang Scholars and Innovative Research Team in University (grant no. PCSIRT:1171).

\section{References}

1. Knackstedt TJ, Brennick JB, Perry AE, Li Z, Quatrano NA and Samie FH: Frequency of squamous cell carcinoma (SCC) invasion in transected SCC in situ referred for Mohs surgery: The Dartmouth-Hitchcock experience. Int J Dermatol 54: 830-833, 2015.

2. Rogers HW, Weinstock MA, Feldman SR and Coldiron BM: Incidence estimate of nonmelanoma skin cancer (keratinocyte carcinomas) in the US population, 2012. JAMA Dermatol 151: 1081-1086, 2015.

3. Sapijaszko M, Zloty D, Bourcier M, Poulin Y, Janiszewski P and Ashkenas J; Canadian Non-melanoma Skin Cancer Guidelines Committee: Non-melanoma skin cancer in Canada chapter 5: Management of squamous cell carcinoma. J Cutan Med Surg 19: 249-259, 2015.

4. Sakura H, Maekawa T, Imamoto F, Yasuda K and Ishii S: Two human genes isolated by a novel method encode DNA-binding proteins containing a common region of homology. Gene 73: 499-507, 1988. 
5. Kudo S, Mattei MG and Fukuda M: Characterization of the gene for $\mathrm{dbpA}$, a family member of the nucleic-acid-binding proteins containing a cold-shock domain. Eur J Biochem 231: 72-82, 1995

6. Balda MS and Matter K: The tight junction protein ZO-1 and an interacting transcription factor regulate ErbB-2 expression. EMBO J 19: 2024-2033, 2000.

7. Wolffe AP: Structural and functional properties of the evolutionarily ancient Y-box family of nucleic acid binding proteins. Bioessays 16: 245-251, 1994

8. Kohno K, Izumi H, Uchiumi T, Ashizuka M and Kuwano M: The pleiotropic functions of the Y-box-binding protein, YB-1. Bioessays 25: 691-698, 2003.

9. Uramoto H, Izumi H, Ise T, Tada M, Uchiumi T, Kuwano M, Yasumoto K, Funa K and Kohno K: p73 Interacts with c-Myc to regulate Y-box-binding protein-1 expression. J Biol Chem 277: 31694-31702, 2002.

10. Sourisseau T, Georgiadis A, Tsapara A, Ali RR, Pestell R, Matter K and Balda MS: Regulation of PCNA and cyclin D1 expression and epithelial morphogenesis by the ZO-1-regulated transcription factor ZONAB/DbpA. Mol Cell Biol 26: 2387-2398, 2006.

11. Tobita H, Kajino K, Inami K, Kano S, Yasen M, Imamura O, Kinoshita $\mathrm{Y}$ and Hino O: Gene expression profile of DNA binding protein A transgenic mice. Int J Oncol 29: 673-679, 2006.

12. Dürr UH, Sudheendra US and Ramamoorthy A: LL-37, the only human member of the cathelicidin family of antimicrobial peptides. Biochim Biophys Acta 1758: 1408-1425, 2006.

13. Bucki R, Leszczynska K, Namiot A and Sokolowski W: Cathelicidin LL-37: A multitask antimicrobial peptide. Arch Immunol Ther Exp (Warsz) 58: 15-25, 2010.

14. Wu WK, Wang G, Coffelt SB, Betancourt AM, Lee CW, Fan D, Wu K, Yu J, Sung JJ and Cho CH: Emerging roles of the host defense peptide LL-37 in human cancer and its potential therapeutic applications. Int J Cancer 127: 1741-1747, 2010.

15. Coffelt SB and Scandurro AB: Tumors sound the alarmin(s). Cancer Res 68: 6482-6485, 2008.

16. Hensel JA, Chanda D, Kumar S, Sawant A, Grizzle WE, Siegal GP and Ponnazhagan S: LL-37 as a therapeutic target for late stage prostate cancer. Prostate 71: 659-670, 2011.

17. Gill K, Mohanti BK, Singh AK, Mishra B and Dey S: The over expression of cathelicidin peptide LL37 in head and neck squamous cell carcinoma: The peptide marker for the prognosis of cancer. Cancer Biomark 10: 125-134, 2011-2012.

18. Kim JE, Kim HJ, Choi JM, Lee KH, Kim TY, Cho BK, Jung JY, Chung KY, Cho D and Park HJ: The antimicrobial peptide human cationic antimicrobial protein-18/cathelicidin LL-37 as a putative growth factor for malignant melanoma. Br J Dermatol 163 959-967, 2010.

19. Heilborn JD, Nilsson MF, Jimenez CI, Sandstedt B, Borregaard N Tham E, Sørensen OE, Weber G and Ståhle M: Antimicrobial protein hCAP18/LL-37 is highly expressed in breast cancer and is a putative growth factor for epithelial cells. Int J Cancer 114: 713-719, 2005

20. Coffelt SB, Waterman RS, Florez L, Höner zu Bentrup K, Zwezdaryk KJ, Tomchuck SL, LaMarca HL, Danka ES, Morris CA and Scandurro AB: Ovarian cancers overexpress the antimicrobial protein hCAP-18 and its derivative LL-37 increases ovarian cancer cell proliferation and invasion. Int J Cancer 122 $1030-1039,2008$

21. von Haussen J, Koczulla R, Shaykhiev R, Herr C, Pinkenburg O, Reimer D, Wiewrodt R, Biesterfeld S, Aigner A and Czubayko F, et al: The host defence peptide LL-37/hCAP-18 is a grow th factor for lung cancer cells. Lung Cancer 59: 12-23, 2008.
22. Coffelt SB, Tomchuck SL, Zwezdaryk KJ, Danka ES and Scandurro AB: Leucine leucine-37 uses formyl peptide receptor-like 1 to activate signal transduction pathways, stimulate oncogenic gene expression, and enhance the invasiveness of ovarian cancer cells. Mol Cancer Res 7: 907-915, 2009.

23. Coffelt SB, Marini FC, Watson K, Zwezdaryk KJ, Dembinski JL, LaMarca HL, Tomchuck SL, Honer zu Bentrup K, Danka ES, Henkle SL and Scandurro AB: The pro-inflammatory peptide LL-37 promotes ovarian tumor progression through recruitment of multipotent mesenchymal stromal cells. Proc Natl Acad Sci USA 106: 3806-3811, 2009.

24. Girnita A, Zheng H, Grönberg A, Girnita L and Ståhle M: Identification of the cathelicidin peptide LL-37 as agonist for the type I insulin-like growth factor receptor. Oncogene 31: 352-365, 2012.

25. Choi KY, Napper S and Mookherjee N: Human cathelicidin LL-37 and its derivative IG-19 regulate interleukin-32-induced inflammation. Immunology 143: 68-80, 2014.

26. Chuang CM, Monie A, Wu A, Mao CP and Hung CF: Treatment with LL-37 peptide enhances antitumor effects induced by $\mathrm{CpG}$ oligodeoxynucleotides against ovarian cancer. Hum Gene Ther 20: 303-313, 2009.

27. Li D, Wang X, Wu JL, Quan WQ, Ma L, Yang F, Wu KY and Wan HY: Tumor-produced versican V1 enhances hCAP18/LL-37 expression in macrophages through activation of TLR2 and vitamin D3 signaling to promote ovarian cancer progression in vitro. PLoS One 8: e56616, 2013.

28. Kittaka M, Shiba H, Kajiya M, Ouhara K, Takeda K, Kanbara K, Fujita T, Kawaguchi H, Komatsuzawa H and Kurihara H: Antimicrobial peptide LL37 promotes vascular endothelial growth factor-A expression in human periodontal ligament cells. J Periodontal Res 48: 228-234, 2013.

29. Yasen M, Kajino K, Kano S, Tobita H, Yamamoto J, Uchiumi T, Kon S, Maeda M, Obulhasim G, Arii S and Hino O: The up-regulation of Y-box binding proteins (DNA binding protein A and Y-box binding protein-1) as prognostic markers of hepatocellular carcinoma. Clin Cancer Res 11: 7354-7361, 2005.

30. Zhang LL, He DL, Li X, Li L, Zhu GD, Zhang D and Wang XY: Overexpression of coxsackie and adenovirus receptor inhibit growth of human bladder cancer cell in vitro and in vivo. Acta Pharmacol Sin 28: 895-900, 2007.

31. Guay D, Garand C, Reddy S, Schmutte C and Lebel M: The human endonuclease III enzyme is a relevant target to potentiate cisplatin cytotoxicity in Y-box-binding protein-1 overexpressing tumor cells. Cancer Sci 99: 762-769, 2008.

32. Wang GR, Zheng Y, Che XM, Wang XY, Zhao JH, Wu KJ, Zeng J, Pan CE and He DL: Upregulation of human DNA binding protein A (dbpA) in gastric cancer cells. Acta Pharmacol Sin 30: 1436-1442, 2009.

33. Koike K, Uchiumi T, Ohga T, Toh S, Wada M, Kohno K and Kuwano M: Nuclear translocation of the Y-box binding protein by ultraviolet irradiation. FEBS Lett 417: 390-394, 1997.

34. Arakawa Y, Kajino K, Kano S, Tobita H, Hayashi J, Yasen M, Moriyama M, Arakawa Y and Hino O: Transcription of dbpA, a $\mathrm{Y}$ box binding protein, is positively regulated by E2F1: Implications in hepatocarcinogenesis. Biochem Biophys Res Commun 322: 297-302, 2004.

35. Bandurska K, Berdowska A, Barczyńska-Felusiak R and Krupa P: Unique features of human cathelicidin LL-37. Biofactors 41: 289-300, 2015

36. Liu J and Du L: PERK pathway is involved in oxygen-glucoseserum deprivation-induced NF- $\kappa$ B activation via ROS generation in spinal cord astrocytes. Biochem Biophys Res Commun 467: $197-203,2015$ 